\title{
Politics of Planetary Reproduction and the Children of Other Worlds
}

\author{
Michael P. Oman-Reagan \\ Vanier Scholar, Department of Anthropology, Memorial University, Canada \\ Affiliated Researcher, University of Victoria, Canada
}

\begin{abstract}
This paper considers possible futures for human space settlements through the life story and experiences of David Vetter-a child born with severe combined immunodeficiency who became known in popular media as the "bubble boy." Lynn Margulis imagined the creation of ecosystems and human settlements on another planet could be an act of Gaia reproducing by budding, through ecopoiesis. Thinking with Margulis about humans as holobionts, our species is both constituted by and embedded within communities of organisms and ecologies. As holobionts we may not be able to live outside of these communities and systems or away from Earth, even if we can temporarily survive without them. Placed within an evolutionary framework, techno-capitalist imaginaries of space settlement limit conceptions of planetary reproduction to heteronormative models of ecopoiesis which promote competition as a key driver of evolution instead of cooperation. Technologically mediated survival along with forced reproduction of holobionts within Earth-like systems and could lead to suffering and isolation like David Vetter's forced survival in a bubble. I propose alternative liberatory modes of conceptualizing and materializing space migration (including queer and decolonized forms of reproduction) which better respect the Earth, its inhabitants, as well as extraterrestrial planets, landscapes, lives, and possibilities.
\end{abstract}

Keywords: Space Settlement, Ecology, Symbiosis, Holobiont, Reproduction

Cite as: "Politics of Planetary Reproduction and the Children of Other Worlds." Futures. (Forthcoming, 2019)

\section{Introduction}

From a holistic perspective the human species is not made up of individual beings, but of embodied ecosystems. We are composed of microbial worlds and situated within multiple relations among many communities-from microbial aggregates to networks of species, planetary ecosystems, and beyond to solar system ecologies. I use this holobiont perspective to consider our species as symbiotic communities of organisms living among other such communities (e.g. Guerrero, et al. 2013).

Conceived as holobionts, humanity emerges from billions of years of symbiogenesis not just on the Earth but with the Earth. Long-term survival as holobionts may depend on this relationship with Earth's currently inimitable microbial ecosystems across the hydro-, cryo-, geo-, and atmo-spheres, and with the aggregates of diverse species adapted to and interacting across those zones. If we cannot live without these systems, should we bring them with us and reproduce our planet on other worlds? How can we include queer modes of reproduction as alternatives to the currently dominant heteronormative discourses of salvation through interplanetary settlement? To explore these politics of planetary reproduction and possible extraterrestrial futures I begin with the life of David Vetter, also known as the "bubble boy."

\section{David's Story}


On September 21st, 1971, David Phillip Vetter was born with severe combined immunodeficiency (SCID). This rare hereditary immune condition prevented him from fighting off infections caused by everyday pathogens. Bacterial, viral, and fungal infections are fatal to people born with SCID-they have almost no working immune system. The condition became known in popular media as "bubble boy disease" following extensive media coverage of David's life in a sterile bubble-like chamber.

Immediately after he was delivered by caesarean in a specially prepared "germ-free" room, David was placed in a sterilized enclosure to ensure isolation. David lived the rest of his life in these "isolator chambers" built by NASA and based on technologies designed to contain moon rocks (Shearer 2004). Research grants from the National Institutes of Health provided USD\$200,000 each year to care for David. His survival was funded as an experiment about germ-free isolation and as a study of his disease and the human immune system.

Unlike other humans who depend on the microbial world, Earth's ecology was a deadly environment for David. Only technology developed for astronauts could protect him. Confined to isolator chambers in the Texas Children's Hospital and then later at home, David was initially only able to travel in an isolation transport chamber. This changed after NASA scientists from the Johnson Space Center designed and built a "space suit" to allow David to walk outside of his bubble for the first time (Cobb n.d.). The "Mobile Biological Isolation System" required three people trained to operate it and only allowed one hour of use (Haggerty 1977).

David was not a happy child playing astronaut, however. When he was in his bubble, he could only interact with other people through plastic gloves in the walls of the isolator chamber. He was terrified of the space suit and of being outside of his isolator bubble. It took him over an hour to transfer into and out of his isolator suit, and he used it only six times before refusing to use it again.

NASA's technology allowed David a few short trips outside, but he was otherwise confined to a life without human contact. To escape this, he imagined adventures exploring outer space and watched science-fiction films like Star Wars, both practices encouraged by psychologists. Ethical questions about David's isolation and agency were barely raised during his life. Reverend Raymond Lawrence, the chaplain of Texas Children's Hospital where David was born, convened the first meetings to discuss the ethics of keeping him isolated in 1975. "The great scandal of the Bubble Boy," Lawrence said, "was that he was conceived for the bubble" (McVicker 1997).

David Vetter was born directly into this unethical experiment, a situation that may have been motivated both by his parent's Catholic faith and his doctor's research interests (Goodman and Maggio 2006). Rev. Lawrence maintains that the doctors convinced David's parents to conceive again after the death of their first son (who was also born with SCID) because they wanted "a test subject for their studies of immunology" (McVicker 1997).

Mary Murphy, a psychology doctoral student at the time, recounted that even though NASA's suit allowed David to walk outside he didn't consider this to be true mobility (McVicker 1997). Murphy observed David becoming increasingly angry and frustrated as he grew older. Speaking at a conference about David's case in 1975 at the University of Virginia, David's first doctor Rafael Wilson was asked how they would respond if David decided he wanted to leave isolation. Wilson replied that "having been raised 
in this from the outset" David could "no more think of removing himself from the bubble than shedding his skin" (Goodman and Maggio 2006).

David's own experience of his isolation was quite different, however, according to reports from those involved in his care (Goodman and Maggio 2006; McVicker 1997). He was plagued by nightmares about germs, fears of people leaving him, and of being trapped in isolation for life. Over the years the doctors who had set up his isolation and promised to cure him slowly left to continue their careers, leaving David in the care of new doctors with little hope of a cure (Goodman and Maggio 2006). David's mother said that after moving from the hospital to their home he would spend the summers sitting silently in his isolator watching children play out the window.

David increasingly questioned his parents' and doctors' decision to isolate him, saying that he wished they had let him die, or had euthanized him, according to Mary Murphy's account (McVicker 1997). As an unwilling subject in an unethical isolation experiment, David was simultaneously kept alive by space-age technology and imprisoned by it until just before his death in 1984, a few months after a failed bone marrow transplant.

Today, new therapies promise better treatments for children born with SCID and long-term isolation is no longer a treatment option (Boodman 2016; Ravin et al. 2016). David's misery was not an inevitable consequence of his illness, but a product of those around him. Instead of using assistive technology to facilitate David's choices and freedom, the medical and technological establishments primarily used it to isolate him. David was isolated from ecological and social environments and taught to fear anything outside of that isolation. He was imprisoned.

The heteronormative ideologies that demanded fulfillment of David's conception, birth, and isolation without regard for David's life were a form of ableism. Such heteronormative ableism permits the existence of bodies, genders, sexualities, families, lives, and futures only when they fulfill normative ideas about reproduction. Such modes of reproduction intentionally isolate offspring from diverse ecological and social relationships in hopes of reproducing mythologized heteronormative individuals such as: the parent, the father, the son, the leader.

David's isolation was constructed using medical and space exploration technology woven together with ideas about reproduction and individualism. David was conceived to be a solitary subject invested with personhood by his parent's Christian god, not by biological, social, or environmental relationships. These myths of individualism also shape the bigotry, racism, borders, capitalism, surveillance, and other structures and practices that imprison so many humans on Earth. When humans migrate into space and become "multiplantary," will we reproduce these stories and their consequences on other worlds as well? As an alternative to the notion of individuals reproducing individuals who are born onto a world made only for them, consider the holistic emergence of holobiont life and the Gaia hypothesis.

\section{Reproducing Gaia}

James E. Lovelock's Gaia hypothesis holds that the surface temperature, chemistry of gases, $\mathrm{pH}$ of atmosphere, and surface of the Earth are maintained by the "metabolism, behavior, growth, and reproduction of living organisms" (Margulis and West 1993, 277). Sometimes misunderstood by both 
scientific communities and popular culture, Lovelock's hypothesis suggests a synthesis of climate, biology, geology, and other science is necessary in order to understand the evolution of life from a planetary science perspective, and the regulation of planetary systems from a life-systems perspective.

Lynn Margulis and Oona West built on the Gaia hypothesis to propose that accomplishing the "colonization" of another planet by Earth organisms would be "exactly equivalent to 'the reproduction of Gaia by budding'" (Margulis and West 1993, 277). Margulis and West rejected the idea of Gaia as a single organism, and instead consider it an "interacting system the components of which are organisms" (1993, 278).

In Margulis and West's politics of planetary reproduction, biospheres built by humans on other worlds would be like planetary spores sent into space by the human component of the Gaia system. The human in space potentially becomes a kind of fruiting body for the planet, part of the mechanism of reproduction. If "the creation of new environments is always the creation of a subject" (Scharmen 2017, 184), then who are the subjects we imagine, and may one day create, in these sporified settlements on other worlds? And what kinds of networks, systems, societies, ecosystems, and other relations do those subjects emerge from and then reproduce and build? If we build better worlds, who are we building them for and to what end?

\section{Solipsism and the Biosphere}

David Vetter's perception of the world was shaped by conditions similar to those one might experience in space or in biospheres on other planets. After growing up in small spaces and isolation, David was afraid of limitless space. He didn't believe buildings had sides other than those he could see, and his experience of the world was often shaped more by time than by space (Kirk 2012).

As a child, the world outside of his isolation chambers seemed flat, unreal. Mary Murphy says that when she asked David to define a tree, he said it was a brown rectangle with a green oval on top; he didn't believe the green oval was made up of branches and leaves until he was shown a branch up close (McVicker 1997). Books, school lessons, and descriptions were unable to compensate for his isolation.

In 1977, the same year NASA engineers built a space suit for David, NASA published "Space Settlements: A Design Study" including an appendix on the "Psychological and Cultural Considerations" of human needs in space (Johnson 1977). In the study, NASA scientists warned about the dangers of "solipsism syndrome" in artificial environments, like space habitats:

Some environments are conducive to the state of mind in which a person feels that everything is a dream and is not real. [...] This state of mind can be easily produced in an environment where everything is artificial [...] where there is nothing beyond the theater stage and beyond an individual's control. [Johnson 1977]

To alleviate this solipsism, the feeling that everything is unreal outside of yourself, NASA proposed solutions built-in to space station designs: a landscape in which something exists beyond what you can easily see, something beyond a horizon; the inclusion of something beyond human control, something 
unpredictable like animals and plants which act differently than we might expect; something that grows, like plants, trees, or vegetables (Johnson 1977). These were all missing from David's life in his isolator.

Solipsism, the NASA study said, is like a nightmare in which nothing seems real and you feel as though there is no reality outside of your own mind. Reverend Lawrence described David as "the first human guinea pig in history, the first human being to live their entire lives in a laboratory capsule," and concluded "I don't think we ought to do that again" (Goodman and Maggio 2006). We must avoid creating a future for humans both on Earth and in space where people are treated like David, as individual subjects living in laboratory capsules alongside other individual subjects. The futures we imagine and build in space and here on Earth must prioritize sociality, ecology, and our holobiont relations.

\section{Colonizing and Terraforming as Violence}

Commercial space ventures and space settlement societies increasingly mythologize terraforming as a utopian remaking of the Martian surface into Earth. Considered from the perspective of Gaia's reproduction, perhaps humans will carry Earth's ecosystem to another world like Mars and nurture it there until it becomes a self-sustaining planetary system. However, terraforming may also manifest as the violent imposition of a particular reproductive ideology on both Gaia's body and other planetary bodies. Terraforming as enforced terranormativity on other worlds would mean the erasure, colonization, and remaking of other planets in Earth's image-the particular image of Earth held by those driving the colonization. Ecopoiesis, the "inundation of a formerly uninhabited surface with viable living systems" is a prerequisite for terraforming but ecopoiesis would also "transform [Mars] into a global cesspool" (Margulis and West 1993, 279); not only ecologically, but also culturally, historically, and socially.

Space industry venture capitalists tell stories about ensuring the survival of our species by becoming multiplanetary. Instead of helping humanity and Gaia, however, these stories are about reproducing and protecting one particular vision of "mankind" based in mythologies of manifest destiny, refusal to acknowledge the legacy and ongoing violence of colonization, and masculinist rocket-measuring contests. The capitalist politics of planetary reproduction and the space settlement plans they envision are violence on multiple levels. Just as David Vetter was forced to survive in isolation at the nexus of scientific hubris and a singular religious ideology, some men want to resurrect 1950s neo-enlightenment mythologies through colonization of other worlds-limiting human futures to their regressive fantasies about technological and civilizational progress on ready-made worlds.

Vetter's doctor was both an immunologist and a catholic priest. Today's techno-utopian priesthood across a globalized Silicon Valley preaches to a choir of tech-bros, singing the praises of a CEO's imagined city on Mars. The hyper-heteronormative colonisers are forcing planetary reproduction on their terms in order to create new frontiers, claim new territories, plant flags, and preserve their technology empires through the expansionism required to keep capitalism afloat.

\section{Decolonizing and Queering Space}

David's doctors were qualified and prepared to place him in a bubble. They solved the technical problems of keeping him alive but failed to consider the aspects of being human beyond the biomedical. Planning 
for space habitation and settlements must include consideration of what it means to be a planetary inhabitant, a holobiont, on Earth now. We must consider relationships among ecosystems, microbial worlds, landscapes, cultures, and societies. We must consider bodily and planetary sovereignty and rights.

Instead of forced heteronormative reproduction through colonization and terraforming, we should consider queer modalities of reproduction and living with other worlds. When space science and speculative fiction imagine "colonizing" Mars or building a generation ship, in which generations of crew live and die during a thousand-year voyage to a distant star (e.g., Ceyssens et al. 2012), we should ask how the diversity of Earth's lives and cultures fit into those visions of reproduction in space. I learn from Lou Cornum (2015) that starting to decolonize space means not only imagining but actively re-building "spaces and times outside the control of colonial powers and white supremacy," not just putting an "indigenous face on the outer space colonizer." Cornum teaches that "not all encounters with the other must end in conquest, genocide or violence ... We do not travel to the distant reaches of space in order to plant our flags or act under the assumption that every planet in our sights is a terra nullius waiting for the first human footprint to mark its surface" (2015).

When we talk about the idea of saving humanity by moving into space, keeping David's life in mind, we should remember there is more than one kind of child. Most children would be excluded from that salvation, just as they are excluded from it today. Queer futurism teaches that "the future is only the stuff of some kids. Racialized kids, queer kids, are not the sovereign princes of futurity" (Esteban Muñoz 2007, 364). Consider also how "child" and "children" have particular meanings in queer Black American vernacular which can further inspire alternative ideas about reproduction. A child can be a member of your family, at any age. Queer communities often create families from social fabric as a survival tactic and explicitly acknowledge within those families the conditions and relations which make that chosen family necessary. A child is a member of a community of built relations, a queer holobiont culturally and ecologically. In this sense, when we talk about space settlement, survival, and salvation we need to ask what it means to survive as a queer child of Earth today.

As a queer person, I can imagine many ways to queer space settlement, as science fiction often does: humans as caretakers of adaptive otherworldly biospheres, lovingly reproducing Earth's ecosystems, parenting gone planetary. But instead of making other worlds conform to human and Terran ecologies, we should consider adapting to the other's differences. Why not embrace our queer sibling planets, Mars and Venus, as valuable for their inhabitability and allow that to shape our descendants' relations with them.

Ideologies about ecosystems and environments have already been exported into space and reimported to be applied on Earth (Anker 2005). What environmental ideologies might return to Earth from isolated settlements on other worlds? Are biospheres enough to reproduce more than bare survival on another world? Will techno-solutionism succeed and dominate multiplanetary futures? So far it has caused planetary crises like anthropogenic climate change and failed to reproduce habitability in limited experiments such as Biosphere 2 (e.g., Mayer 2016).

There is much to critique and to queer in today's dominant visions of space settlement. Queer, Black, Trans, BIPOC (Black, Indigenous, and People of Colour), and drag queen communities have long used the practice of "reading" as a tool for critically looking at creative invention of self, of communities, 
and of possible futures (e.g. Livingston 1990). Reading is "the real art form of insult" (Livingston 1990). If you find a flaw in what someone is trying to create and exaggerate it to make it apparent, that's a read. In the documentary film Paris is Burning, Dorian Corey of the New York City ballroom scene explains that reading developed into shade (in which the critique is so clear it doesn't even need to be spoken), and then voguing came from shade (Livingston 1990). Voguing is a performative, communicative dance that communicates shade through poses as competition, critique, reference, and gesture. The ballroom scene where this form of dance-debate arose was a direct response to the fact the participating marginalized communities had "everything taken away" from them and yet "learned how to survive" (Livingston 1990).

I am here to critically read the issues brought up by space settlement, alongside the perspectives of others who have also learned to survive oppression here on Earth. This debate needs other participants, not just more heterosexual, white, cis-gendered men. The conversation about space is already colonized, already too straight, already increasingly deadly for everyone else. The debate needs to make room for people who can further read the assumptions of space colonizers when they say reproduction, habitability, colonization, futures, salvation. The space settlement discussion needs more shade. We need to ask: Futures for whom?

It is not enough to provide living beings with food, air, entertainment, and a place to sleep. Technosolutionism and capitalism cannot solve the problems of moving Earth life into space and onto other worlds. We must prioritize intentional relations and the social, environmental, and cultural aspects of life on Earth which are essential to what we, and others, are as holobionts. To live in space, we first need to queer and decolonize what it means for a world to be habitable here on Earth. As David's story reminds us, life is much more than reproduction and bare survival. We need to acknowledge, address, and repair the inhabitability and injustices we have built and continue to build on our own planet. We must water, fertilize, and tend the seeds of alternative visions of futures in space, not only seeking solutions to earthly problems, but actively queering outer space and challenging our futures to be even more queer. A better world is possible here on Earth and perhaps, one day, out there in space as well.

\section{Funding}

This research was supported by the Social Sciences and Humanities Research Council of Canada. 


\section{References Cited}

Anker, P. (2005). The Ecological Colonization of Space. Environmental History, 10, 239-268.

Boodman, E. (2016, April 20). New gene therapy offers treatment for "bubble boy" disease. Retrieved February 2, 2017, from https://www.statnews.com/2016/04/20/gene-therapy-scid/

Ceyssens, F., Driesen, M., \& Wouters, K. (2012). On the Organisation of World Ships and Other Gigascale Interstellar Space Exploration Projects. Journal of the British Interplanetary Society, 65, 134-139.

Cobb, J. (n.d.). David Vetter Isolation Suit | Bullock Texas State History Museum. Retrieved February 2, 2017, from https://www.thestoryoftexas.com/discover/artifacts/david-vetter-suit-spotlight-010816

Cornum, L. (2015, January 26). The Space NDN’s Star Map. The New Inquiry. Retrieved from https://thenewinquiry.com/the-space-ndns-star-map/

Esteban Muñoz, José. 2007. "Cruising the Toilet: LeRoi Jones/Amiri Baraka, Radical Black Traditions, and Queer Futurity." GLQ: A Journal of Lesbian and Gay Studies 13 (2): 353-67.

Goodman, B., \& Maggio, J. (2006). The Boy in the Bubble. WGBH Educational Foundation and Ark Media LLC for American Experience in association with Channel 4. Retrieved from http://www.pbs.org/wgbh/amex/bubble/filmmore/filmcredits.html

Guerrero, R., Margulis, L., \& Berlanga, M. (2013). Symbiogenesis: the holobiont as a unit of evolution. International Microbiology: The Official Journal of the Spanish Society for Microbiology, 16(3), 133-143. https://doi.org/10.2436/20.1501.01.188

Haggerty, J. J. (1977). Spinoff 1977 (Annual Report No. 20070019874) (p. 120). Washington, DC, United States: NASA. Retrieved from https://ntrs.nasa.gov/search.jsp?R $=20070019874$

Johnson, R. D. (1977). Space Settlements: A Design Study. NASA SP-413. NASA Special Publication, 413. Retrieved from http://adsabs.harvard.edu/abs/1977NASSP.413.....

Kirk, R. G. W. (2012). "Life in a Germ-Free World": Isolating Life from the Laboratory Animal to the Bubble Boy. Bulletin of the History of Medicine, 86(2), 237-275. https://doi.org/10.1353/bhm.2012.0028

Livingston, J. (1990). Paris is Burning. Miramax.

Margulis, L., \& West, O. (1993). Gaia and the Colonization of Mars. GSA Today, 3(11), 277-291. 
Mayer, R. (2016). Beyond the Blue Marble: Artistic research on space and ecology. Acta Astronautica, 128, 573-579. https://doi.org/10.1016/j.actaastro.2016.08.015

McVicker, S. (1997, April 10). Bursting the Bubble. Houston Press. Retrieved from

http://www.houstonpress.com/news/bursting-the-bubble-6573830

Ravin, S. S. D., Wu, X., Moir, S., Kardava, L., Anaya-O'Brien, S., Kwatemaa, N., ... Malech, H. L. (2016). Lentiviral hematopoietic stem cell gene therapy for X-linked severe combined immunodeficiency. Science Translational Medicine, 8(335), 335ra57-335ra57. https://doi.org/10.1126/scitranslmed.aad8856

Scharmen, Fred. 2017. "Highest and Best Use: Subjectivity and Climates Off and After Earth." Journal of Architectural Education 71 (2): 184-96. https://doi.org/10.1080/10464883.2017.1340775.

Shearer, W. T. (2004). Importance of technology for the future of allergy and immunology. Journal of Allergy and Clinical Immunology, 114(2), 406-408. https://doi.org/10.1016/j.jaci.2004.06.031 